\title{
STUDI EKSISTENSI DYNAMIC TRADE-OFF CAPITAL STRUCTURE PADA PERUSAHAAN NON-FINANSIAL DI BEI PERIODE 2002-2009
}

\author{
Leo Atansil \\ Endang Ernawati (endangernawati@yahoo.com) \\ Universitas Surabaya
}

\begin{abstract}
This research aims to analyze the factors which affect capital structure and also discover the existence of dynamic trade-off capital structure. Variables which use are profitability, tangibility, size, growth, non-debt tax shields, and operating risk. This research use quantitative approach by using multiple linier regression. This research use samples in the form of non-financial company which are listed in Indonesian Stock Exchange on 2002-2009. Final samples which are utilized in this research are equal to 375 observation. Research finding indicates that profitability, tangibility, and size doesn't affect significantly to capital structure. Growth, non-debt tax shields, and operating risk give significantly negative effect to capital structure. This research also finds that the company doing adjustment exceeds the level required to achieve the optimum debt (over-adjustment) so that the company's capital structure are not optimum.
\end{abstract}

Keywords: capital structure, profitability, tangibility, size, growth, non-debt tax shields, and operating risk

\section{LATAR BELAKANG}

Financing merupakan salah satu fungsi manajemen keuangan yang cukup strategis selain fungsi investasi, karena kedua fungsi ini mempunyai pengaruh langsung terhadap maksimisasi nilai perusahaan. Putusan pembiayaan berkaitan dengan pemilihan serta penentuan bauran modal yang optimal, yaitu kombinasi dari berbagai jenis modal yang mengandung biaya modal paling murah. Sementara itu, biaya modal berfungsi sebagai tingkat diskonto dari arus kas proyek-proyek investasi yang dilakukan oleh perusahaan. Semakin rendah biaya modal, dengan arus kas proyek tertentu, akan mengakibatkan semakin tinggi nilai perusahaan, demikian pula sebaliknya. Dengan demikian, struktur modal memiliki peran penting dalam menentukan nilai perusahaan, sehingga pihak manajer harus mampu mengambil keputusan yang mengoptimalkan struktur modal, karena pada akhirnya dapat meningkatkan dan memaksimumkan nilai perusahaan. Modigliani dan Miller (1963) dalam Megginson (1997: 323) secara implisit menyatakan bahwa di satu sisi struktur modal dapat meningkatkan nilai perusahaan, namun di sisi lain dapat meningkatkan risiko kebangkrutan, yang berarti menurunkan nilai perusahaan tersebut.

Berkaitan dengan pentingnya struktur modal dalam menentukan nilai perusahaan, Muradoglu dan Sivaprasad (2006) meneliti pengaruh leverage terhadap firm value pada perusahaan yang terdaftar di London Stock Exchange (LSE) selama periode 1980 sampai dengan 2004. Sampel yang diambil adalah sejumlah 792 perusahaan dan digolongkan ke dalam beberapa kelas risiko. Hasil penelitian menunjukkan bahwa variabel leverage berpengaruh signifikan terhadap firm value, walaupun pada kelas risiko tertentu memiliki hubungan negatif, dan pada kelas risiko lainnya memiliki hubungan positif.

Ghosh (2003) meneliti pengaruh dividend policy, leverage dan profitabilitas terhadap firm value pada 500 perusahaan yang terdaftar di S\&P periode 1989 sampai dengan 2002. Hasil penelitian menunjukkan adanya pengaruh positif yang signifikan dari variabel dividend dan profitabilitas terhadap firm value. Sedangkan variabel leverage memiliki hubungan negatif signifikan terhadap firm value. Sementara Gemmill (2001) meneliti pengaruh struktur modal 
terhadap firm value pada perusahaan di UK yang memiliki karakteristik split-capital closedend funds pada tahun 2000. Jumlah populasi yang sesuai dengan karakteristik adalah 76 perusahaan. Hasil penelitian menunjukkan bahwa struktur modal dapat meningkatkan firm value.

Dalam hubungannya dengan struktur modal ini, Akhtar (2002) berpendapat bahwa apabila keberadaan struktur modal benar-benar mampu memaksimumkan firm value, maka diperlukan pemahaman mengenai faktor-faktor yang dapat mempengaruhi struktur modal dalam rangka memahami cara untuk memaksimumkan firm value. Di sisi lain, variabelvariabel yang berpengaruh terhadap struktur modal telah menjadi penelitian yang terus berkembang sejak literatur Miller dan Modigliani dipublikasikan. Berbagai teori muncul dengan pandangan masing-masing dalam menjelaskan perilaku penentuan struktur modal suatu perusahaan. Di antara berbagai teori struktur modal, trade-off theory dan pecking order theory adalah yang paling mendominasi (Bouallegui, 2006). Studi empiris yang dilakukan oleh para peneliti di berbagai wilayah/negara hingga saat ini telah memberi banyak kontribusi bagi kedua teori tersebut, baik berupa konfirmasi atau kontradiksi.

Rajan dan Zingales (1995) meneliti determinan dari struktur modal pada perusahaan go public di negara G-7 (US, Japan, Germany, France, Italy, UK, Canada) periode 1987 sampai dengan 1991. Hasil penelitian menunjukkan bahwa size, tangibility, growth, dan profitability berpengaruh signifikan terhadap struktur modal, namun memiliki korelasi yang beragam untuk masing-masing negara. Abor \& Biekpe (2005) meneliti penentu-penentu dari struktur modal untuk semua perusahaan yang terdaftar di Ghanaian Stock Exchange selama periode 1998-2003. Ditemukan bahwa variabel growth dan size memiliki pengaruh positif terhadap struktur modal, sedangkan variabel tangibility, profitability, dan non-debt tax shields memiliki pengaruh negatif-signifikan. Sedangkan Drobetz \& Fix (2003) meneliti penentu-penentu dari struktur modal pada 124 perusahaan Swiss yang terdaftar di Swiss Performance Index. Ditemukan bahwa variabel tangibility dan size berpengaruh positif signifikan dengan struktur modal dan variabel growth, profitability, dan volatility berpengaruh negatif signifikan dengan struktur modal. Sedangkan variabel non-debt tax shield dan uniqueness memiliki pengaruh yang tidak signifikan. Sedangkan Darminto (2008) melakukan pengujian terhadap trade-off theory dan pecking order theory pada kelompok perusahaan industrials (berdasarkan kategori OSIRIS) yang terdaftar di Bursa Efek Indonesia periode 2002 sampai dengan 2006. Penelitian menggunakan 37 perusahaan. Hasil penelitian menunjukkan bahwa tangibility dan size berpengaruh signifikan positif terhadap struktur modal, sedangkan non-debt tax shields berpengaruh signifikan negatif terhadap struktur modal. Dalam penelitian ini, disimpulkan bahwa trade-off theory lebih mampu menjelaskan perilaku struktur modal daripada pecking order theory. Penelitian ini juga mengukur speed of adjustment menuju target debt ratio (optimum capital structure) suatu perusahaan, dimana optimum capital structure merupakan sebuah pemikiran yang lahir dari perspektif trade-off theory.

Penelitian mengenai target debt ratio juga dilakukan oleh Bouallegui (2006). Penelitian dilakukan pada 99 perusahaan industri hi-tech di Jerman periode 1998 sampai dengan 2002. Hasil penelitian menemukan bahwa size, tangibility, dan non-debt tax shields memiliki pengaruh signifikan dengan korelasi positif terhadap struktur modal, sedangkan profitability dan operating risk berpengaruh signifikan dan negatif terhadap struktur modal. Selain itu, penelitian ini juga menemukan bahwa perusahaan industri hi-tech di Jerman melakukan penyesuaian terhadap target debt ratio dengan sangat cepat.

Gaud et al. (2003) meneliti hubungan sejumlah explanatory variable terhadap dinamika struktur modal pada perusahaan yang terdaftar di Swiss Stock Exchange (SWX) periode 1991 sampai dengan 2000 dengan karakteristik non financial company. Didapat sejumlah 106 perusahaan sebagai sampel. Hasil penelitian menunjukkan bahwa perusahaan di SWX memiliki slow speed of adjustment terhadap target debt ratio. Hubungan variabel yang ditemukan adalah size, tangibility, dan risk berpengaruh signifikan positif terhadap struktur 
modal, sedangkan growth dan profitability berpengaruh signifikan negatif terhadap struktur modal.

Beberapa penelitian lain mengenai speed of adjustment ke arah target debt ratio telah dilakukan oleh Clark et al. (2007), Flannery dan Rangan (2004), serta Zhao dan Susmel (2008). Graham dan Harvey (1999) melakukan penelitian dengan data primer mengenai cost of capital, capital budgeting, dan capital structure. Survey dilakukan terhadap 392 CFO perusahaan di US. Survey mengenai capital structure membuktikan bahwa $81 \%$ perusahaan mempertimbangkan target debt ratio baik secara spesifik maupun dengan range tertentu, dalam membuat keputusan struktur modal.

Adanya adjustment ke arah predicted leverage menjelaskan bahwa perusahaan memiliki suatu target debt ratio. Hal tersebut membuktikan keberadaan trade-off theory dengan cara melihat perilaku struktur modal secara dinamis. Seperti yang telah dipaparkan dalam penelitian Gaud et al. (2003), Clark et al. (2007), Flannery dan Rangan (2004), serta Zhao dan Susmel (2008), terdapat praktik trade-off dimana perusahaan melakukan penyesuaian struktur modal ke arah target debt ratio secara berkelanjutan, yang disebut dynamic tradeoff capital structure.

Dari hasil penelitian yang telah dipaparkan, diketahui terdapat 6 variabel yang berpengaruh signifikan terhadap struktur modal suatu perusahaan yaitu size, profitability, tangibility, non-debt tax shields, operating risk, dan growth. Dengan demikian, penelitian ini akan menggunakan 6 variabel tersebut serta variabel struktur modal yang diukur dengan debt.

Penelitian akan dilakukan pada perusahaan non-finansial yang terdaftar di Bursa Efek Indonesia (BEI) periode 2002-2009. Sektor finansial tidak digunakan sebagai obyek penelitian karena perusahaan dalam sektor tersebut umumnya memiliki regulasi khusus sehingga sangat mempengaruhi proses pendanaannya (Gaud et al., 2003). Rajan dan Zingales (1995) menyatakan bahwa sektor finansial memiliki tingkat debt yang tidak comparable dibandingkan sektor non-finansial. Selain itu, adanya berbagai macam regulasi seperti minimum capital requirements dapat secara langsung mempengaruhi struktur modal perusahaan sektor finansial sehingga menjadi tidak relevan apabila digunakan bersamaan dengan sektor non-finansial dalam penelitian yang terkait struktur modal.

Tujuan yang hendak dicapai dalam penelitian ini adalah untuk mengetahui pengaruh size, profitability, tangibility, non-debt tax shields, operating risk, dan growth terhadap capital structure pada perusahaan non-finansial yang terdaftar di BEl periode 2002-2009. Selain itu, penelitian ini juga bertujuan untuk mengetahui gambaran keberadaan dynamic trade-off capital structure pada perusahaan non-finansial yang terdaftar di BEl periode 2002-2009.

Berdasarkan latar belakang masalah, identifikasi masalah, dan ruang lingkup masalah, maka dirumuskan permasalahan sebagai berikut:

1. Apakah terdapat pengaruh size, profitability, tangibility, non-debt tax shields, operating risk, dan growth terhadap capital structure pada badan usaha nonfinansial yang terdaftar di BEl periode 2002-2009?

2. Bagaimana gambaran keberadaan dynamic trade-off capital structure pada badan usaha non-finansial yang terdaftar di BEl periode 2002-2009?

Dari perumusan masalah, tujuan yang hendak dicapai adalah untuk mengetahui pengaruh size, profitability, tangibility, non-debt tax shields, operating risk, dan growth terhadap capital structure pada badan usaha non-finansial yang terdaftar di BEl periode 2002-2009. Selain itu, penelitian ini juga bertujuan untuk mengetahui gambaran keberadaan dynamic trade-off capital structure pada badan usaha non-finansial yang terdaftar di BEl periode 2002-2009. 


\title{
LANDASAN TEORI DAN PENGEMBANGAN HIPOTESIS
}

\author{
Struktur Modal
}

Struktur modal merupakan kombinasi dari utang jangka panjang dan ekuitas dalam struktur keuangan suatu perusahaan (Megginson, 1997: 305 dan Gitman, 2006: 538). Struktur keuangan perusahaan tercermin pada sisi kanan neraca, yang terdiri dari current liabilities, long-term debt dan stockholder's equity. Sementara struktur modal adalah bagian dari struktur keuangan yang lebih memperhatikan modal jangka panjang dan permanen. Kondisi bauran utang jangka panjang dan ekuitas yang efisien disebut sebagai struktur modal optimal. Dengan mengoptimalkan struktur modal, cost of capital menjadi semakin rendah sehingga nilai perusahaan akan meningkat.

Utang, selain dapat memainkan peran untuk meningkatkan nilai perusahaan juga dapat difungsikan untuk menekan biaya keagenan. The agency theory berpendapat bahwa pengawasan dapat dilakukan oleh pemegang saham dengan mengundang pihak eksternal perusahaan yaitu kreditur (Mahadwartha, 2004). Dengan adanya utang maka manajemen memiliki kewajiban tetap atas utang (fixed payment), sehingga dapat mengurangi konflik keagenan yang disebabkan oleh tindakan investasi berlebihan oleh manajemen. Kebijakan utang merupakan salah satu alternatif untuk memindahkan biaya pengawasan oleh pemilik kepada kreditur, penggunaan utang juga mendorong manajer untuk lebih bertindak disiplin agar tidak terancam kebangkrutan (Megginson, 1997:335). Utang menyebabkan perusahaan harus membayar bunga secara periodik serta adanya kewajiban pembayaran prinsipal, sehingga akan mengurangi kontrol manajer terhadap aliran kas perusahaan dalam kegiatan yang tidak optimal (Jensen dan Meckling, 1976).

Berkaitan dengan penggunaan utang dalam struktur modal, terdapat tiga teori utama yang menjelaskan struktur modal perusahaan, yaitu trade-off theory, pecking order theory, dan the signaling model of financial structure (Megginson, 1997: 315). Trade-off theory berasumsi bahwa struktur modal perusahaan merupakan hasil dari proses pertimbangan antara benefit dan cost yang didapat dari peningkatan penggunaan utang (Megginson, 1997: 315). Utang sebagai sumber pendanaan eksternal bermanfaat dalam mengurangi pajak (Gitman, 2006: 555). Pengurangan ini terjadi karena interest yang dibayar perusahaan kepada bondholders akan mengurangi earnings before interest and taxes (EBIT) sehingga nilai earnings before taxes (EBT) akan menjadi semakin rendah. Dengan demikian, semakin banyak proporsi utang dalam struktur modal akan semakin banyak pula tax benefit.

Di sisi lain, peningkatan utang dapat meningkatkan financial distress. Terdapat 2 jenis biaya dalam financial distress yaitu direct bankruptcy costs dan indirect bankruptcy costs (Ross et al., 2003: 553). Direct bankruptcy costs adalah biaya yang dikeluarkan perusahaan secara langsung terkait dengan bangkrutnya perusahaan, sedangkan indirect bankruptcy costs adalah biaya-biaya yang dikeluarkan perusahaan untuk menghindari kebangkrutan.

Semakin tinggi penggunaan utang, maka semakin tinggi risiko ketidakmampuan perusahaan dalam memenuhi pembayaran bunga. Hal ini berarti probabilitas gagal bayar suatu perusahaan (financial distress) juga semakin tinggi. Selain itu, adanya peningkatan risiko menyebabkan debtholders menuntut return yang semakin tinggi. Hal tersebut akan berdampak pada kenaikan cost of debt sehingga pada akhirnya akan menurunkan nilai perusahaan.

Trade-off theory memprediksi bahwa perusahaan mempertahankan struktur modal yang optimal dimana marginal benefit sama dengan marginal costs dalam penggunaan utang (Cotei dan Farhat, 2009). Implikasi dari model ini adalah adanya target debt ratio dimana perusahaan selalu melakukan penyesuaian ke arah titik optimal tersebut.

Pecking Order Theory memiliki dua asumsi kunci yaitu adanya asymmetric information dan 
manajer bertindak atas kepentingan existing shareholders (Megginson, 1997: 315). Manajer lebih mengetahui nilai dan risiko perusahaan yang sebenarnya daripada investor. Untuk menghindari masalah underinvestment, manajer akan mendanai proyek baru dengan sumber dana yang tidak mengalami undervalued di pasar seperti internal funds atau riskless debt (Cotei dan Farhat, 2009). Hal tersebut mengakibatkan adanya pilihan antara sumber dana internal dan eksternal dalam pecking order theory.

Pecking order theory menyatakan bahwa perusahaan akan mengutamakan pendanaan dengan utang daripada ekuitas apabila sumber internal tidak mampu memenuhi kebutuhan pendanaan perusahaan (Bouallegui, 2006). Perusahaan memiliki urutan pilihan dalam pendanaan yaitu dimulai dari pendanaan internal (retained earnings, akumulasi depresiasi), kemudian pendanaan eksternal dengan risiko yang paling rendah, hingga risiko yang paling tinggi.

Dalam pecking order theory, struktur modal bukan merupakan hasil dari proses pertimbangan antara benefit dan cost dari penggunaan utang, namun merupakan hasil kumulatif dari upaya manajer untuk mengurangi information asymmetry (Cotei dan Farhat, 2009). Hal ini berarti pecking order theory tidak menjelaskan adanya target debt ratio dalam suatu perusahaan.

The Signaling Model of Financial Structure juga menggunakan asumsi asymmetric information. Penjelasan yang dikemukakan adalah bahwa manajer akan memberikan sinyal-sinyal tertentu kepada investor untuk menunjukkan bahwa perusahaan yang mereka kelola adalah yang paling kompeten (Megginson, 1997: 315). Sinyal tersebut tentunya menimbulkan biaya yang tinggi dan tidak mudah dilakukan oleh kompetitor. Salah satu bentuk sinyal yang dilakukan adalah dengan menerapkan tingkat utang yang tinggi pada struktur modal. Hanya perusahaan kuat yang mampu menghadapi risiko financial distress yang tinggi akibat penerapan struktur modal tersebut.

Debt

Debt adalah semua pinjaman jangka panjang yang dilakukan perusahaan, termasuk bonds (Gitman, 2006: 326). Debt merupakan sumber pendanaan eksternal selain ekuitas. Dalam kegiatan bisnisnya, perusahaan dapat menggunakan debt sebagai alternatif untuk meningkatkan kemampuan pendanaan bilamana dana internal seperti laba ditahan tidak mencukupi kebutuhan. Karena itu debt dikenal pula dengan istilah leverage.

Penggunaan debt dapat mengurangi jumlah pajak yang harus dibayar oleh perusahaan karena pembayaran interest dari debt menyebabkan earnings before taxes berkurang. Selain itu penggunaan debt juga mampu meningkatkan firm value karena nilai weighted average cost of capital (WACC) menjadi semakin rendah.

Debt dapat diukur dengan market value dan book value. Dalam penelitian ini, debt ratio dari book value akan digunakan sebagai alat ukur untuk variabel debt (Bouallegui, 2006). Book value debt ratio dipilih sesuai pernyataan Mackay \& Philips (2005) dalam Chen \& Strange (2005), bahwa penggunaan debt ratio dengan market value of debt maupun book value of debt akan memberi hasil yang sama. Manajer seringkali menggunakan nilai buku dalam mengambil keputusan, dan data mengenai corporate debt sangat terbatas, sehingga market value of debt tidak digunakan. Debt ratio diukur dengan membagi total long-term debt dengan jumlah total long-term debt dan total equity.

$$
\text { Debt ratio }=\frac{\text { long }- \text { term debt }}{\text { long }- \text { term debt }+ \text { total equity }}
$$


Growth

Growth adalah pertumbuhan perusahaan untuk mempertahankan posisi usahanya melalui penjualan (Mazur, 2007). Akhtar (2002) menyatakan bahwa growth diukur dengan pertumbuhan total assets. Dengan bertumbuhnya penjualan, maka kapasitas perusahaan juga harus ditingkatkan melalui tambahan investasi pada aset, sehingga pertumbuhan aset mencerminkan growth suatu perusahaan. Ukuran dari growth adalah persentase perubahan total assets.

Growth $=\frac{\text { total assets }(t)-\text { total assets }(t-1)}{\text { total assets }(t-1)}$

Gaud et al. (2003), Rajan dan Zingales (1995), serta Titman dan Wessels (1988), Chung (1993), Barclay et al. (1995) dalam Bouallegui (2006) menyatakan bahwa growth memiliki hubungan yang negatif terhadap debt. Dengan utang yang tinggi, kontrol manajer terhadap aliran kas perusahaan akan semakin lemah karena perusahaan harus membayar bunga secara periodik serta adanya kewajiban membayar prinsipal. Hal tersebut menyebabkan perusahaan cenderung melepas berbagai peluang investasi dengan NPV positif (growth options) karena pengaruh debtholder yang konservatif. Dengan demikian, perusahaan yang memiliki peluang growth tinggi akan cenderung mengurangi penggunaan utang agar lebih mudah untuk merealisasikan growth options yang ada. Jadi, semakin tinggi growth suatu perusahaan, maka semakin rendah debt dari perusahaan tersebut.

Size

Definisi size menurut Bouallegui (2006) adalah besar kecilnya suatu perusahaan yang dapat diukur dengan menggunakan aset total perusahaan tersebut. Kegiatan bisnis yang sehat diharapkan mampu mengembangkan ukuran perusahaan. Size dapat dikaitkan dengan kemudahan dalam memperoleh pendanaan melalui utang. Ukuran size adalah logaritma dari aset total.

Size $=$ Log. Total assets

Drobetz \& Fix (2003) menyatakan bahwa size memiliki hubungan yang positif terhadap debt. Semakin besar size suatu perusahaan, maka semakin rendah probability of bankruptcy perusahaan tersebut (Titman dan Wessels, 1988, dalam Bouallegui, 2006; Rajan dan Zingales, 1995). Dalam trade-off theory, perusahaan dengan risiko kebangkrutan yang masih rendah akan meningkatkan debt hingga mencapai titik optimal tertentu. Dengan demikian, size yang semakin besar dapat dikaitkan dengan penggunaan debt yang semakin tinggi. Ferri dan Jones (1979) dalam Bouallegui (2006) menambahkan bahwa perusahaan dengan size besar cenderung lebih mudah dalam melakukan pendanaan utang. Jadi, semakin tinggi size suatu perusahaan, maka semakin tinggi debt dari perusahaan tersebut.

Profitability

Profitability adalah kemampuan perusahaan dalam menghasilkan laba setelah terjadi pengurangan antara pendapatan dengan biaya-biaya perusahaan (Gitman, 2006: 629). Profitability berkaitan erat dengan keputusan pendanaan. Perusahaan dengan profitability yang tinggi memiliki kemampuan yang baik dalam menyediakan dana internal. Rasio profitability juga digunakan untuk melihat seberapa efektif perusahaan dalam menghasilkan laba dari penggunaan sumber daya produksinya. Hal tersebut menjadi salah satu pertimbangan kreditur, sehingga perusahaan dengan profitability yang tinggi akan lebih mudah untuk mendapatkan utang daripada perusahaan dengan profitability yang buruk.

Profitability diukur dengan rasio operating profit (EBIT) terhadap aset total perusahaan (Deesomsak et al., 2004; Flannery dan Rangan, 2004). Penggunaan operating profit lebih dipilih daripada net profit karena operating profit terjadi sebelum perusahaan melakukan 
pembayaran interest sehingga lebih mencerminkan efektifitas perusahaan secara utuh dalam mengelola aset yang dimiliki. Sedangkan net profit hanya mencerminkan profitability perusahaan dari sudut pandang shareholders karena unsur interest telah dihilangkan.

Profitability $=\frac{E B I T}{\text { total assets }}$

Bouallegui (2006), Gaud et al. (2003), Abor \& Biekpe (2005), serta Drobetz \& Fix (2003) menyatakan bahwa profitability memiliki pengaruh negatif terhada debt. Sesuai pecking order theory, perusahaan dengan profitabilitas yang tinggi memiliki kemampuan yang baik dalam memenuhi kebutuhan financing melalui sumber internal sehingga semakin tinggi profitability maka kebutuhan akan pendanaan eksternal (dalam hal ini debt) akan semakin rendah. Jadi, semakin tinggi profitability suatu perusahaan, maka semakin rendah debt dari perusahaan tersebut.

Tangibility

Tangibility adalah keberwujudan aset yang dimiliki suatu perusahaan. Aset berwujud dikaitkan dengan informational asymmetries yang lebih rendah dan biasanya memiliki nilai yang lebih tinggi dibandingkan dengan aset tidak berwujud pada kondisi kebangkrutan (Gaud et al., 2003).

Jika dikaitkan dengan struktur modal, maka aset berwujud jangka panjang dapat digunakan sebagai collateral dalam mendapatkan biaya utang yang lebih murah. Alat ukur tangibility menurut Bouallegui (2006) adalah rasio dari aset berwujud terhadap aset total.

$$
\text { Tangibility }=\frac{\text { tangible fixed assets }}{\text { total assets }}
$$

Rajan dan Zingales (1995), serta Fama dan French (2000) dalam Bouallegui (2006) menyatakan bahwa tangibility memiliki hubungan yang positif dengan debt. Tangible assets dapat digunakan sebagai jaminan dalam mendapatkan biaya utang yang lebih murah. Semakin tinggi tangible assets perusahaan, maka semakin besar jaminan yang dapat diberikan kepada lenders. Rendahnya biaya utang merupakan suatu keuntungan bagi perusahaan sehingga hal tersebut dapat dimanfaatkan dengan menggunakan utang yang lebih besar. Jadi, semakin tinggi tangibility suatu perusahaan, maka semakin tinggi debt dari perusahaan tersebut.

Non-Debt Tax Shields

Menurut Deesomsak et al. (2004), definisi non-debt tax shields adalah komponen pada investasi untuk mengurangi pajak tanpa menggunakan utang. Dalam trade-off theory, motivasi utama dalam penggunaan utang adalah untuk mengurangi beban pajak. Dengan demikian maka non-debt tax shields merupakan komponen yang sejalan dengan tujuan tersebut. Ukuran untuk non-debt tax shield adalah rasio depreciation terhadap total assets (Mazur, 2007).

$$
\text { Nondebt tax shield }=\frac{\text { depreciation }}{\text { total assets }}
$$

Campbell \& Jerzemowska (2001; 71) dalam Drobetz \& Fix (2003), serta Shenoy dan Koch (1996) dalam Bouallegui (2006) menyatakan bahwa terdapat hubungan negatif antara nondebt tax shields dengan debt. Perusahaan dengan non-debt tax shields yang tinggi mengindikasikan bahwa terdapat komponen selain utang yang dapat mengurangi pajak tanpa harus menggunakan utang. Sehingga perusahaan akan menggunakan komponen selain utang untuk mengurangi beban pajak, karena penggunaan utang meningkatkan beban keuangan perusahaan. Jadi, semakin tinggi non-debt tax shields suatu perusahaan, maka semakin rendah debt dari perusahaan tersebut. 


\section{Operating Risk}

Operating risk adalah tingkat volatilitas pendapatan dari fungsi bisnis perusahaan (Abor dan Biekpe, 2005). Semakin tinggi volatilitas earnings stream suatu perusahaan, maka semakin besar peluang kebangkrutan dari perusahaan tersebut. Berkaitan dengan struktur modal, perusahaan dengan operating risk yang tinggi cenderung dinilai buruk oleh kreditur sehingga akan mengalami kesulitan dalam mendapatkan pendanaan utang. Berdasarkan penelitian Bouallegui (2006), maka ukuran untuk operating risk adalah kuadrat dari selisih profitabilitas perusahaan dengan rata-rata profitabilitas seluruh perusahaan (cross section mean).

Operating risk $\left.=(\text { cross section mean of profitability }- \text { profitability })^{2}\right)$

Kremp et al. (1999) dalam Bouallegui (2006) serta Drobetz \& Fix (2003) menyatakan bahwa operating risk memiliki hubungan yang negatif dengan debt. Semakin tinggi operating risk suatu perusahaan, maka semakin besar peluang kebangkrutan dari perusahaan tersebut. Debt yang tinggi juga diasosiasikan dengan peluang kebangkrutan yang tinggi dari suatu perusahaan. Dengan demikian, perusahaan dengan operating risk yang tinggi cenderung menggunakan debt yang rendah guna mengurangi peluang kebangkrutan tersebut.

Proses Penyesuaian ke Arah Optimum Capital Structure

Dalam trade-off theory, dinyatakan bahwa suatu perusahaan melakukan proses trade-off antara cost dan benefit dalam menggunakan debt sehingga pada akhirnya akan menemukan suatu tingkat debt yang optimal. Namun adanya perubahan berbagai kondisi menyebabkan tingkat debt yg dianggap optimal juga berubah-ubah. Ketika perubahan tersebut terjadi, perusahaan akan melakukan pertimbangan ulang mengenai cost-benefit dalam menggunakan debt dan menemukan titik debt optimal yang baru. Proses pertimbangan dan penyesuaian yang dilakukan secara terus-menerus itu disebut dynamic trade-off capital structure. Proses penyesuaian dilakukan secara parsial maupun secara penuh.

Keberadaan dynamic trade-off capital struture dapat diketahui dengan melihat apakah perilaku pergerakan tingkat debt aktual mengarah pada target debt optimal atau tidak. Dengan demikian, penelitian ini berupaya untuk mengetahui bagaimana gambaran keberadaan dynamic trade-off capital structure dengan cara tersebut.

Adanya adjustment ke arah predicted leverage menjelaskan bahwa perusahaan memiliki suatu target debt ratio. Hal tersebut membuktikan keberadaan trade-off theory dengan cara melihat perilaku struktur modal secara dinamis. Seperti yang telah dipaparkan dalam penelitian Gaud et al. (2003), Clark et al. (2007), Flannery dan Rangan (2004), serta Zhao dan Susmel (2008), terdapat praktik trade-off dimana perusahaan melakukan penyesuaian struktur modal ke arah target debt ratio secara berkelanjutan, yang disebut dynamic tradeoff capital structure.

Dalam sebagian besar penelitian, penyesuaian perusahaan untuk target-target keuangan dianggap seketika dan gratis. Dalam pasar yang sempurna, penyesuaian terhadap targettarget jangka panjang akan seketika (instantaneous) dan menyelesaikan (complete). Namun, ketidaksempurnaan pasar seperti biaya transaksi dan penyesuaian serta beberapa kendala mencegah perusahaan dari mengubah tingkat atau rasio utang mereka dengan cara yang mereka inginkan (Marsh, 1982; Jalilvand dan Harris, 1984). Karena ketidaksempurnaan pasar ini keputusan keuangan perusahaan harus dilihat sebagai proses dua tahap. Tahap pertama merupakan pembentukan target dan tahap kedua adalah penyesuaian terhadap tingkat utang yang ditetapkan dalam tahap pertama. Oleh karena itu, perilaku keuangan perusahaan yang terbaik ditandai dengan model penyesuaian parsial (Spies, 1974; Taggart Jr, 1977; Jalilvand dan Harris, 1984; Ozkan, 2001). Pernyataan ini 
menguatkan pendapat bahwa penyesuaian secara parsial lebih dipilih oleh perusahaan daripada penyesuaian secara penuh.

Hipotesis

Berdasarkan latar belakang masalah, identifikasi masalah, dan ruang lingkup masalah yang telah diungkapkan, maka dapat dirumuskan hipotesis mayor sebagai berikut:

1. Diduga terdapat pengaruh negatif antara profitability dengan debt pada perusahaan non-finansial di BEl periode 2002-2009.

2. Diduga terdapat pengaruh yang positif antara tangibility dengan debt pada perusahaan non-finansial di BEl periode 2002-2009.

3. Diduga terdapat pengaruh yang positif antara size dengan debt pada perusahaan non-finansial di BEl periode 2002-2009.

4. Diduga terdapat pengaruh yang negatif antara growth dengan debt pada perusahaan non-finansial di BEl periode 2002-2009.

5. Diduga terdapat pengaruh yang negatif antara non-debt tax shields dengan debt pada perusahaan non-finansial di BEl periode 2002-2009.

6. Diduga terdapat pengaruh yang negatif antara operating risks dengan debt pada perusahaan non-finansial di BEl periode 2002-2009.

\section{METODE PENELITIAN}

Jenis Penelitian

Penelitian ini merupakan penelitian kausal yang bertujuan untuk menguji pengaruh dari variabel-variabel ukuran perusahaan, kebijakan utang, dan profitabilitas terhadap kebijakan dividen. Teknik yang digunakan adalah eksperimen dengan pendekatan kuantitatif.

Variabel dan Definisi Operasional

Berdasarkan metode analisis dan hipotesis penelitian, maka variabel-variabel dalam penelitian ini dapat dibedakan menjadi satu variabel dependen dan enam variabel independen. Variabel dependen (dependent variabel) dalam penelitian ini yaitu capital structure yang diukur dengan debt. Sedangkan variabel bebas (independent variabel) dalam penelitian ini yaitu growth, size, profitability, tangibility, non-debt tax shields, dan operating risk.

Tabel 1: Variabel, Definisi Operasional, dan Pengukurannya

\begin{tabular}{|c|c|c|}
\hline Variabel & Definisi Operasional & Pengukuran \\
\hline Debt & $\begin{array}{l}\text { pinjaman yang diterima dari } \\
\text { pihak eksternal }\end{array}$ & $\begin{array}{l}\text { Debt ratio = longterm debt / (longterm } \\
\text { debt + total equity) }\end{array}$ \\
\hline Growth & $\begin{array}{l}\text { persentase pertumbuhan nilai } \\
\text { aset total }\end{array}$ & $\begin{array}{l}\text { Growth }=(\text { total assets }+- \text { total assets } t-1) \\
/ \text { total assets }{ }_{t-1}\end{array}$ \\
\hline Size & $\begin{array}{l}\text { Ukuran perusahaan berdasarkan } \\
\text { aset total }\end{array}$ & Size $=$ Log.Total assets \\
\hline Profitability & $\begin{array}{l}\text { kemampuan perusahaan dalam } \\
\text { menghasilkan laba }\end{array}$ & $\begin{array}{l}\text { Profitability = } \\
\text { EBIT / total assets }\end{array}$ \\
\hline Tangibility & $\begin{array}{l}\text { aset tetap yang memiliki wujud } \\
\text { fisik sebagai bentuk investasi } \\
\text { perusahaan }\end{array}$ & $\begin{array}{l}\text { Tangibility = tangible fixed assets / } \\
\text { total assets }\end{array}$ \\
\hline $\begin{array}{l}\text { Non-Debt Tax } \\
\text { Shields }\end{array}$ & $\begin{array}{l}\text { komponen pada investasi } \\
\text { perusahaan untuk pengurangan } \\
\text { pajak tanpa menggunakan } \\
\text { utang }\end{array}$ & $\begin{array}{l}\text { Non-debt tax shields = depreciation / } \\
\text { total assets }\end{array}$ \\
\hline Operating Risk & $\begin{array}{l}\text { volatilitas pendapatan dari fungsi } \\
\text { bisnis perusahaan }\end{array}$ & $\begin{array}{l}\text { operating risk = } \\
\text { (cross section mean of profitability - } \\
\text { profitability)2 }\end{array}$ \\
\hline
\end{tabular}


Populasi dan Sampel

Populasi dalam penelitian ini adalah semua perusahaan non-finansial yang terdaftar di Bursa Efek Indonesia dengan periode pengamatan tahun 2002-2009. Karakteristik populasi yang digunakan adalah: (1) Menerbitkan laporan keuangan yang runtut setiap tahun selama periode 2002-2009 dan telah diaudit; (2) Tidak sedang dalam proses delisting. Sampel yang digunakan dalam penelitian ini berjumlah 75 perusahaan.

Data

Data yang digunakan adalah data sekunder berupa laporan keuangan perusahaanperusahaan yang dijadikan sampel. Data tersebut diperoleh dari Osiris, Indonesian Capital Market Directory (ICMD), laporan keuangan dari www.idx.co.id, dan Pusat Database Laboratorium Manajemen Keuangan Fakultas Bisnis dan Ekonomika Universitas Surabaya.

\section{Analisis Regresi}

Penelitian ini menggunakan metode pengolahan data regresi linier berganda karena untuk mengetahui secara langsung pengaruh variabel independen terhadap variabel dependen. Tahapan dalam analisis regresi linear berganda, adalah: pertama, menentukan nilai dari variabel-variabel untuk setiap perusahaan yang dipilih selama periode penelitian; kedua, mengidentifikasi gejala asumsi klasik dengan tujuan agar model regresi dapat menghasilkan penduga yang tidak bias (sahih). Pengujian normalitas menggunakan Kolmogorov-Smirnov, multikolinearitas menggunakan variance inflation fantor (VIF), autokorelasi mengacu pada nilai Durbin Watson, heteroskedastisitas menggunakan uji Park atau Glesjer. Ketiga, melakukan analisis regresi dengan menggunakan model regresi linear berganda.

Persamaan yang digunakan dalam penelitian ini merupakan pengembangan dari static model. Dengan pengembangan tersebut, gambaran keberadaan dynamic trade-off capital structure dapat diketahui disamping hubungan antara variabel bebas dan terikat. Persamaan yang digunakan mengacu pada penelitian Bouallegui (2006) sebagai berikut:

$$
Y_{i t}=a_{i}+\psi Y_{i t-1}+\beta x_{i t}+e_{i t} \quad \ldots \ldots \ldots \ldots \ldots \ldots \ldots \ldots \text { (1) }
$$

$Y_{\text {it }}$ adalah debt perusahaan i pada periode $t$, $a_{i}$ adalah konstanta i, $\Psi$ adalah koefisien regresi atau $(1-\lambda), \lambda$ adalah adjustment parameter, $Y_{i t-1}$ adalah debt perusahaan i pada periode $t-1, \beta$ adalah koefisien regresi, $\quad x_{i t}$ adalah variabel penelitian perusahaan i pada periode $t$, dan eit adalah tingkat kesalahan (standard error).

Nilai $\lambda$ merupakan parameter yang digunakan untuk mengetahui gambaran keberadaan dynamic trade-off capital structure. Apabila $\lambda=1$, berarti perusahaan melakukan adjustment secara penuh, sehingga pada periode † perusahaan berada pada kondisi debt optimal. Apabila $\lambda<1$, berarti proses adjustment pada periode $t-1$ menuju periode $t$ kurang dari tingkat yang dibutuhkan untuk mencapai debt yang optimal. Hal tersebut menjelaskan bahwa perusahaan melakukan adjustment secara parsial. Apabila $\lambda>1$, berarti proses adjustment pada periode $t-1$ menuju periode $t$ melebihi tingkat yang dibutuhkan untuk mencapai debt yang optimal (over adjusment).

Dengan menggunakan persamaan (1), maka harus dilakukan pengujian untuk mengetahui apakah model berada dalam kondisi fixed effect atau random effect. Hal tersebut disebabkan karena estimator yang akan digunakan dalam proses pengolahan data harus dibedakan untuk masing-masing kondisi. Berdasarkan penelitian Anderson dan Hsiao (1982) dalam Bouallegui (2006), maka pengujian tersebut dapat diabaikan dengan menggunakan transformasi pada model. Transformasi dilakukan dengan menggunakan first differences untuk masing-masing variabel, sehingga menjadi persamaan berikut:

$$
Y_{i t}-Y_{i t-1}=a_{i}+\Psi\left(Y_{i t-1}-Y_{i t-2}\right)+\beta\left(X_{i t}-X_{i t-1}\right)+e_{i t}-e_{i t-1}
$$


Berdasarkan persamaan (2) tersebut, maka bentuk persamaan utuh yang digunakan dalam penelitian ini adalah sebagai berikut:

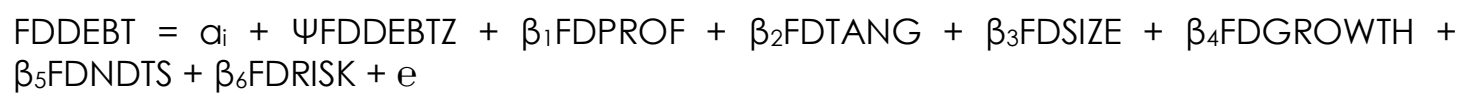

FDDEBT adalah long-term debt perusahaan i pada periode $\dagger$ dikurangi long-term debt perusahaan i pada periode $t-1, a_{i}$ adalah konstanta, $\psi$ adalah 1 - adjustment parameter, FDDEBTZ adalah long-term debt perusahaan i pada periode t- 1 dikurangi longterm debt perusahaan i pada periode t-2, FDPROF adalah profitability perusahaan i pada periode $\dagger$ dikurangi profitability perusahaan i pada periode $t-1$, FDTANG adalah tangibility perusahaan i pada periode $t$ dikurangi tangibility perusahaan i pada periode $t-1$, FDSIZE adalah size perusahaan i pada periode t dikurangi size perusahaan i pada periode $t-1$, FDGROWTH adalah growth perusahaan i pada periode $t$ dikurangi growth perusahaan $\mathrm{i}$ pada periode t-1, FDNDTS adalah non-debt tax shields perusahaan i pada periode $\dagger$ dikurangi non-debt tax shields perusahaan i pada periode t-1, FDRISK adalah operating risks perusahaan i pada periode $\dagger$ dikurangi operating risks perusahaan i pada periode $t-1, \beta_{1}, \beta_{2}$, $\beta_{3}, \beta_{4}, \beta_{5}, \beta_{6}$ adalah koefisien regresi, dan e adalah standar error periode $\dagger$ dikurangi standar error periode t-1.

Keempat, mengukur kemampuan menjelaskan variabel bebas terhadap variabel terikat. Indikator yang digunakan adalah koefisien determinasi $\left(\mathrm{R}^{2}\right)$. Besarnya $\mathrm{R}^{2}$ merupakan alat untuk mengukur seberapa baik model regresi dapat digunakan sebagai alat prediksi. Sedangkan pengujian hipotesis dilakukan dengan menggunakan uji $F$ untuk pengujian secara serempak dan uji t untuk pengujian secara parsial dengan tingkat signifikansi sebesar $5 \%$.

\section{HASIL DAN PEMBAHASAN}

Sampel yang digunakan dalam penelitian ini berjumlah 75 perusahaan non-finansial periode 2002-2009 yang memenuhi persyaratan yang telah ditentukan sebelumnya. Data-data yang digunakan dalam penelitian ini diolah dengan menggunakan metode regresi linier berganda dan pengolahan data tersebut mengunakan program Microsoft Excel 2007, SPSS 17.0 for Windows, serta Eviews 4.0 for Windows.

Data Penelitian

Data yang digunakan merupakan penyesuaian dari transformasi model yang telah dijelaskan pada bab III. Transformasi model tersebut menyebabkan data variabel asli diubah dengan menggunakan first difference yaitu mengurangkan nilai variabel pada periode $\dagger$ dengan nilai variabel itu sendiri pada periode $t-1$, sehingga variabel yang digunakan merupakan perubahan masing-masing varibel dari periode $t-1$ menuju periode $t$.

Statistik deskriptif menjelaskan gambaran karakteristik-karakteristik dari sampel penelitian yang mewakili populasinya. Karakteristik sampel yang dimaksud dalam penelitian ini meliputi jumlah observasi, nilai rata-rata (mean), standar deviasi dan koefisien variasi untuk masingmasing variabel penelitian yang diukur. Berikut ini akan disertakan tampilan data descriptive table untuk meringkas data-data yang digunakan di dalam penelitian ini.

Dari tabel 6, terlihat bahwa jumlah observasi (n) dalam penelitian ini adalah 375 . Variabel yang memiliki nilai rata-rata (mean) yang tertinggi terdapat pada first differences variabel size (FDSIZE) perusahaan yaitu sebesar 0,125, sedangkan untuk standar deviasi tertinggi dimiliki oleh first differences variabel lag-debt (FDDEBTZ) sebesar 3,447 dan terendah dimiliki oleh first differences variabel tangibility (FDTANG) yaitu sebsar 0,087. Semakin tinggi nilai dari 
standar deviasi menandakan bahwa semakin besar rentangan nilai yang dimiliki oleh variabel tersebut.

Tabel 2. Statistik Deskriptif

\begin{tabular}{|l|r|r|r|r|r|r|r|r|}
\hline Variabel & \multicolumn{1}{|c|}{ FDPROF } & \multicolumn{1}{l|}{ FDTANG } & \multicolumn{1}{l|}{ FDSIZE } & FDGROW & \multicolumn{1}{l|}{ FDNDTS } & \multicolumn{1}{l|}{ FDRISK } & \multicolumn{1}{l|}{ FDDEBT } & FDDEBTZ \\
\hline Mean & 0,003216 & $-0,005721$ & 0,125309 & $-0,048384$ & 0,002157 & 0,001774 & $-0,126946$ & $-0,008309$ \\
\hline Maximum & 1,333822 & 0,403322 & 2,550039 & 11,719470 & 1,186360 & 1,422685 & 22,012930 & 34,245500 \\
\hline Minimum & $-1,243183$ & $-0,847834$ & $-0,856989$ & $-10,400800$ & $-1,020718$ & $-1,432620$ & $-38,279290$ & $-38,279300$ \\
\hline Std. Dev. & 0,119760 & 0,087472 & 0,331630 & 1,057672 & 0,094305 & 0,107396 & 3,172978 & 3,447400 \\
\hline Obs. & 375 & 375 & 375 & 375 & 375 & 375 & 375 & 375 \\
\hline
\end{tabular}

Sumber: Hasil print-out

Hasil Penelitian dan Pembahasan

Sebelum melakukan analisis regresi linear berganda, terlebih dahulu akan dilakukan uji normalitas dan uji kecocokan model. Pengujian normalitas dilakukan dengan menggunakan Kolmogorov-Smirnov terhadap nilai residual. Dari hasil pengujian tersebut didapatkan hasil Kolmogorov-Smirnov Z sebesar 7,316 dan nilai asymp.sig (2 tailed) 0,000 . Nilai tersebut menunjukkan bahwa data tidak berdistribusi normal dikarenakan nilai signifikansi yang lebih kecil dari 0,05. Namun, terdapat beberapa asumsi kenormalan yang dapat memberikan pembenaran teoritis untuk normalitas suatu data. Gujarati (2004:109) menyatakan bahwa "....it can be shown that if those are a large number of independent and identically distributed random variables, then with a view exceptions the distribution of their sum tends to a normal distribution...".

Gujarati (1995:782) juga mengklasifikasikan variabel dengan $n>25$ merupakan sampel yang besar. "......., based on $n=25$ is biased since its sampling distributed is not only tends to be more closely centered on (i.e...., becomes less biased) but its variance also become smaller". Oleh karena itu dengan jumlah data setiap variabel yang cukup banyak yaitu 375 data, sehingga dengan sendirinya data akan normal.

Pengujian asumsi klasik dilakukan agar data terbebas dari gejala multikolinearitas, autokorelasi, dan heteroskedastisitas. Untuk mengetahui data yang digunakan bebas dari multikolinearitas maka dapat dilihat dari nilai VIF yang dihasilkan dari pengolahan data. Hasil tes multikolinieritas untuk variabel FDPROF memiliki nilai sebesar 2,459, variabel FDTANG sebesar 1,035, variabel FDSIZE sebesar 1,106, variabel FDGROW sebesar 1,278, variabel FDNDTS sebesar 1,381, variabel FDRISK sebesar 2,507, dan variabel FDDEBTZ 1,030. Dari hasil diatas dapat diketahui bahwa nilai VIF untuk seluruh variabel $<5$ sehingga dapat disimpulkan bahwa model di dalam penelitian ini tidak terjadi multikolinearitas.

Hasil pengujian autokorelasi menunjukkan hasil perhitungan Durbin Watson sebesar 1,844. Dari tabel diketahui bahwa dengan jumlah observasi (n) sebesar 375 dan variabel independen $(k)$ sebesar 7, sehingga diperoleh $d_{L}=1,79$ dan $d u=1,86$. Kesimpulan yang dapat ditarik adalah model regresi berada pada grey area.

Pengujian heteroskedastisitas di dalam penelitian ini menggunakan uji Park. Berdasarkan hasil yang didapat diketahui bahwa nilai sig adalah sebesar 0,392. Nilai ini $>0,05$, sehingga dapat disimpulkan bahwa penelitian ini bebas dari heterokedastisitas.

Hasil analisis regresi linear berganda dengan menggunakan program Eviews 4.0 for Windows menghasilkan persamaan sebagai berikut ini. 
Tabel 3. Hasil Analisis Regresi Linear Berganda

\begin{tabular}{|c|c|c|c|c|}
\hline \multicolumn{5}{|c|}{ 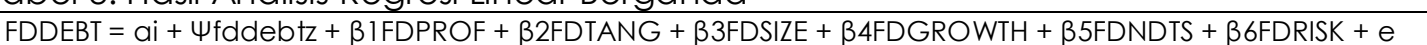 } \\
\hline Variabel & $\begin{array}{c}\text { Koefisien } \\
\text { Regresi }\end{array}$ & Signifikansi & $\begin{array}{l}\text { Hubungan yang } \\
\text { diharapkan }\end{array}$ & $\begin{array}{c}\text { Penerimaan/Penolakan } \\
\text { Hipotesis }\end{array}$ \\
\hline Konstanta & $-0,2084$ & 0,203 & & \\
\hline FDDEBTZ & $-0,3686$ & $0,000^{* *}$ & & \\
\hline FDPROF & 2,7100 & 0,171 & Negatif & Ditolak \\
\hline FDTANG & $-1,2109$ & 0,490 & Positif & Ditolak \\
\hline FDSIZE & 0,4756 & 0,321 & Positif & Ditolak \\
\hline FDGROWTH & $-0,3853$ & $0,017^{* *}$ & Negatif & Diterima \\
\hline FDNDTS & $-3,7129$ & $0,049^{* *}$ & Negatif & Diterima \\
\hline FDRISK & $-4,1936$ & $0,060^{* * *}$ & Negatif & Diterima pada level sig $10 \%$ \\
\hline F-Statistic & 10,6340 & $0,000^{*}$ & & \\
\hline R-Squares & & & 0,168 & \\
\hline $\begin{array}{ll}\text { Adjusted } & \text { R- } \\
\text { Squares } & \end{array}$ & & & 0,152 & \\
\hline
\end{tabular}

Hasil uji $\mathrm{F}$ sebesar 10,634 dengan tingkat signifikansi 0,000 atau $<5 \%$ yang berarti bahwa variabel independen (debtt-1, profitability, tangibility, size, growth, non-debt tax shields, operating risk) secara bersama-sama mempengaruhi variabel dependen (debt) secara signifikan. Dengan demikian, model tersebut dapat digunakan untuk memprediksi variabel first difference dari debt.

Variabel profitability mempunyai pengaruh positif-tidak signifikan terhadap debt karena memiliki nilai signifikansi sebesar 0,171. Hasil tersebut membuktikan bahwa hipotesis 1 ditolak. Hubungan positif ini menunjukkan bahwa jika variabel profitability mengalami kenaikan maka menyebabkan kenaikan pada variabel debt, dan begitu pula sebaliknya. Berdasarkan trade-off theory, perusahaan dengan profitabilitas yang tinggi akan cenderung menggunakan debt yang lebih besar untuk meningkatkan tax shield ( Rajan dan Zingales, 1995). Peningkatan debt tersebut dimungkinkan karena perusahaan memiliki kemampuan yang baik dalam melakukan pembayaran interest. Pengaruh yang tidak signifikan disebabkan karena peningkatan profitabilitas digunakan untuk pembayaran utang. Tabel 5 menunjukkan peningkatan profitability pada periode 2005,2007, dan 2008 diikuti oleh penurunan tingkat debt.

Variabel tangibility mempunyai pengaruh negatif-tidak signifikan terhadap debt karena memiliki nilai signifikansi sebesar 0,49. Hasil tersebut membuktikan bahwa hipotesis 2 ditolak. Hubungan negatif ini menunjukkan bahwa jika variabel tangibility mengalami kenaikan maka menyebabkan penurunan pada variabel debt, dan begitu pula sebaliknya. Hal ini sesuai dengan penelitian Abor \& Biekpe (2005). Pengaruh negatif tersebut dapat disebabkan karena peningkatan tangible fixed assets dilakukan dengan sumber pendanaan berupa ekuitas, sehingga akan mengurangi proporsi debt dalam struktur modal perusahaan.

Variabel size mempunyai pengaruh positif-tidak signifikan terhadap debt karena memiliki nilai signifikansi sebesar 0,321. Hasil tersebut membuktikan bahwa hipotesis 3 ditolak. Hubungan positif ini menunjukkan bahwa jika variabel size mengalami kenaikan maka menyebabkan kenaikan pada variabel debt, dan begitu pula sebaliknya. Pengaruh yang tidak signifikan disebabkan karena perusahaan dengan ukuran besar memiliki informational asymmetries yang lebih rendah sehingga akan lebih mudah dalam menerbitkan sekuritas yang sensitif terhadap informasi pasar seperti ekuitas. Dengan demikian, perusahaan tersebut memiliki kecenderungan untuk memilih pendanaan melalui ekuitas (Rajan dan Zingales, 1995).

Variabel growth mempunyai pengaruh negatif-signifikan terhadap debt karena memiliki nilai signifikansi sebesar 0,017 (signifikan pada level 5\%). Hasil tersebut membuktikan bahwa hipotesis 4 diterima. Hubungan negatif ini menunjukkan bahwa jika variabel growth 
mengalami kenaikan maka menyebabkan penurunan pada variabel debt, dan begitu pula sebaliknya. Hal ini sesuai dengan penelitian Gaud et al. (2003) dan Titman dan Wessels (1988), Chung (1993), Barclay et al. (1995) dalam Bouallegui (2006), yang menyatakan bahwa dengan debt yang tinggi, kontrol manajer terhadap aliran kas perusahaan akan semakin lemah karena perusahaan harus membayar bunga secara periodik serta adanya kewajiban pembayaran prinsipal. Hal tersebut menyebabkan perusahaan cenderung melepas berbagai peluang investasi dengan NPV positif (growth options) karena pengaruh debtholder yang konservatif. Dengan demikian, perusahaan yang memiliki peluang growth tinggi akan cenderung mengurangi penggunaan debt agar lebih mudah untuk merealisasikan growth options yang ada. Perusahaan yang memiliki growth tinggi cenderung menggunakan debt yang rendah agar manajer dapat merealisasikan growth options dengan mudah, tanpa pengawasan yang kuat dari debtholder. Dengan lemahnya pengawasan debtholder, maka implikasi bagi shareholder adalah akan memiliki peluang yang lebih besar untuk mendapatkan return yang lebih tinggi dari investasi yang dipilih manajer. Namun lemahnya pengawasan debtholder akan meningkatkan agency problem antara manajer dan investor, serta meningkatkan peluang terjadinya moral hazart. Penggunaan debt yang rendah juga dapat menurunkan firm value karena rendahnya proporsi cost of debt dalam cost of capital. Selain itu, dengan terbatasnya sumber pendanaan, maka terdapat kemungkinan perusahaan hanya membagikan sedikit dividen, terutama apabila perusahaan menggunakan dana internal untuk mendanai proyek. Bagi pihak manajer, growth yang tinggi mengindikasikan adanya kebutuhan dana apabila ingin merealisasikan growth options yang ada. Dengan rendahnya penggunaan debt, maka alternatif sumber pendanaan yang tersisa untuk memenuhi kebutuhan tersebut adalah dana internal dan ekuitas. Konsekuensi dari penggunaan ekuitas adalah meningkatnya cost of capital akibat peningkatan proporsi ekuitas.

Variabel non-debt tax shields mempunyai pengaruh negatif-signifikan terhadap debt karena memiliki nilai signifikansi sebesar 0,049 (signifikan pada level 5\%). Hasil tersebut membuktikan bahwa hipotesis 5 diterima. Hubungan negatif ini menunjukkan bahwa jika variabel nondebt tax shields mengalami kenaikan maka menyebabkan penurunan pada variabel debt, dan begitu pula sebaliknya. Hal ini sesuai dengan penelitian Campbell \& Jerzemowska (2001; 71) dalam Drobetz \& Fix (2003), serta Shenoy dan Koch (1996) dalam Bouallegui (2006). Perusahaan dengan non-debt tax shields yang tinggi mengindikasikan bahwa terdapat komponen selain utang yang dapat mengurangi pajak tanpa harus menggunakan utang. Dengan demikian, perusahaan akan menggunakan komponen selain utang untuk mengurangi beban pajak, karena penggunaan utang meningkatkan beban keuangan perusahaan. Perusahaan yang memiliki non-debt tax shields tinggi cenderung menggunakan debt yang rendah. Dengan non-debt tax shields tinggi, perusahaan tidak perlu meningkatkan debt untuk mengurangi beban pajak, sehingga tidak akan terjadi peningkatan risiko kegagalan dalam membayar interest akibat penambahan debt. Implikasi atas hal tersebut bagi pihak manajer adalah terbatasnya pendanaan yang dapat dilakukan dengan debt serta tersedianya dana internal yang lebih banyak untuk diinvestasikan kembali. Apabila pihak manajer memutuskan untuk melakukan pendanaan proyek dengan ekuitas, maka cost of capital akan meningkat.

Variabel operating risk mempunyai pengaruh negatif-tidak signifikan terhadap debt karena memiliki nilai signifikansi sebesar 0,06 (signifikan pada level 10\%). Hasil tersebut membuktikan bahwa hipotesis 6 diterima. Hubungan negatif ini menunjukkan bahwa jika variabel operating risk mengalami kenaikan maka menyebabkan penurunan pada variabel debt, dan begitu pula sebaliknya. Hal ini sesuai dengan penelitian Kremp et al. (1999) dalam Bouallegui (2006) serta Drobetz \& Fix (2003). Semakin tinggi operating risk (volatilitas earning) suatu perusahaan, maka semakin besar peluang kegagalan dalam membayar interest dari perusahaan tersebut. Karena itu, perusahaan dengan operating risk yang tinggi cenderung menggunakan debt yang rendah guna mengurangi jumlah interest yang harus dibayar. Dengan demikian, risiko kebangkrutan akan berkurang. Bagi pihak manajer, tingginya operating risk mengakibatkan pendanaan yang dapat dilakukan terbatas hanya pada 
dana internal dan ekuitas, demi menekan risiko kegagalan dalam membayar interest. Apabila pihak manajer memutuskan untuk melakukan pendanaan proyek dengan ekuitas, maka cost of capital akan mengalami peningkatan.

Variabel debt $t_{-1}$ memiliki koefisien regresi $(\Psi)$ sebesar $-0,368$ atau $\lambda$ sebesar 1,368 . Nilai $\lambda$ tersebut memiliki makna bahwa adjustment pada periode $t-1$ menuju periode $\dagger$ lebih dari tingkat yang dibutuhkan untuk mencapai debt yang optimal (over-adjusment). Secara empiris, nilai debt yang optimal sulit untuk dicapai. Hal ini bisa disebabkan karena perusahaan belum tentu dapat menentukan nominal debt maupun jangka waktu pinjaman yang sesuai dengan proporsi dalam optimum capital structure.

Koefisien determinasi (adjusted R-squared) adalah sebesar 0,152. Hal ini menunjukkan bahwa perubahan debt dapat dijelaskan oleh variabel debtt-l, profitability, tangibility, size, growth, non-debt tax shields dan operating risk sebesar $15,2 \%$, sedangkan sisanya sebesar $84,8 \%$ dijelaskan oleh variabel-variabel di luar variabel debtt-1, profitability, tangibility, size, growth, non-debt tax shields dan operating risk.

Untuk proses adjustment menuju tingkat debt yang lebih rendah, kondisi over-adjustment disebabkan karena perusahaan menciptakan financial slack. Financial slack adalah suatu kondisi dimana perusahaan memiliki ketersediaan kas atau kapasitas debt, sehingga ketika terdapat peluang investasi yang baik di masa mendatang, perusahaan dapat segera menggunakan kas atau melakukan pendanaan dengan memanfaatkan kapasitas debt yang tersisa untuk merealisasikan peluang investasi tersebut.

Untuk proses adjustment menuju tingkat debt yang lebih tinggi, kondisi over-adjustment disebabkan karena perusahaan memiliki kecenderungan untuk memanfaatkan fasilitas debt yang ada semaksimal mungkin. Kondisi over-adjusment tersebut mengakibatkan firm value tidak optimal dimana dapat tercermin dalam berbagai rating perusahaan (company rating) sebagaimana disajikan pada tabel 8 berikut ini.

Tabel 4. Company Rating Berbagai Badan Usaha Nonfinancial di BEl Periode 2002-2009

\begin{tabular}{|l|c|l|}
\hline \multicolumn{1}{|c|}{ Badan Usaha } & Periode & \multicolumn{1}{c|}{ Rating } \\
\hline BLTA & 2007 & idea \\
\hline BRAM & 2007 & idA- \\
\hline BRNA & 2009 & Baa3id \\
\hline ELTY & 2009 & idBBB+ \\
\hline GJTL & 2005 & idBBB \\
\hline MEDC & $2007-2009$ & idAA- \\
\hline MPPA & 2007 & idA \\
\hline PWON & 2009 & BBB- (idn) \\
\hline RICY & 2007 & BBB+ \\
\hline RICY & 2009 & Baalid \\
\hline SMRA & 2005 & idBBB \\
\hline SMRA & 2009 & idBBB + \\
\hline
\end{tabular}

Sumber: IDX dan FEFINDO, diolah

\section{SIMPULAN}

Berdasarkan hasil penelitian dan diskusi yang telah dilakukan, maka dapat dibuat beberapa konklusi dan rekomendasi yang dapat dijadikan bahan pertimbangan bagi pihak-pihak yang berkepentingan.

Simpulan

Berdasarkan pengujian hipotesis dengan menggunakan uji $\mathrm{F}$, diperoleh hasil bahwa variabel profitability, tangibility, size, growth, non-debt tax shields, operating risk, serta variabel debtt-l 
berpengaruh secara serempak dan signifikan terhadap debt pada perusahaan nonfinansial yang terdaftar pada PT Bursa Efek Indonesia selama periode 2002-2009. Hal ini menandakan bahwa model dapat digunakan untuk memprediksi capital structure (debt).

Berdasarkan hasil pengujian hipotesis dengan melakukan uji $t$, dapat diketahui bahwa variabel growth mempunyai pengaruh negatif-signifikan terhadap debt, variabel non-debt tax shields mempunyai pengaruh negatif-signifikan terhadap debt, dan variabel operating risk mempunyai pengaruh negatif-signifikan terhadap debt pada perusahaan non-finansial yang terdaftar pada PT Bursa Efek Indonesia selama periode 2002-2009. Selain itu, diketahui bahwa perusahaan tersebut berada dalam kondisi debt yang tidak optimal, dimana terjadi over-adjustment pada proses penyesuaian struktur modalnya. Hal ini dapat diketahui dari nilai adjustment parameter ( $\lambda$ ) sebesar 1,368 atau lebih besar dari 1. Berdasarkan hasil ini dapat dikatakan bahwa perusahaan non-finansial yang terdaftar pada PT Bursa Efek Indonesia periode 2002-2009 melakukan adjusment melebihi tingkat yang dibutuhkan untuk mencapai debt optimal (over-adjustment), sehingga perusahaan tersebut berada pada kondisi capital structure yang tidak optimal.

Berdasarkan nilai koefisien determinasi (adjusted R-squared) sebesar 0,152, diketahui bahwa variabel-variabel independen dalam penelitian ini yaitu profitability, tangibility, size, growth, non-debt tax shields, operating risk, serta variabel debtt-l mampu menjelaskan debt sebesar $15,2 \%$, sedangkan sisanya sebesar $84,8 \%$ dijelaskan oleh variabel lain di luar penelitian ini.

\section{Rekomendasi}

Bagi pihak manajer yang ingin mendanai investasi dengan utang sekaligus meningkatkan nilai perusahaan tanpa meningkatnya beban keuangan yang besar harus memperhatikan growth, non-debt tax shields, dan operating risk pada perusahaan. Hal ini dikarenakan variabel tersebut berpengaruh secara signifikan terhadap debt. Dengan growth, non-debt tax shields, dan operating risk yang tinggi, pihak manajer harus mempertimbangkan keputusan pendanaan terbaik diantara dana internal maupun ekuitas, karena keterbatasan sumber pendanaan utang. Disamping itu, pemilihan proyek juga harus dilakukan dengan lebih berhati-hati karena pengawasan dari debtholder berkurang. Dengan kontrol yang lebih tinggi, manajer mungkin saja menjadi lalai terhadap pertimbangan risiko yang lebih spesifik dan hanya memperhatikan return dari suatu proyek. Apabila manajer memutuskan pendanaan dengan ekuitas, maka tingkat return yang diharapkan harus telah mempertimbangkan peningkatan cost yang terjadi tanpa mengesampingkan risiko yang timbul.

Bagi investor yang cenderung bersifat risk seeker, dapat mempertimbangkan investasi pada perusahaan dengan growth dan non-debt tax shields yang tinggi. Karena kondisi tersebut memungkinkan perusahaan untuk memilih proyek dengan return yang lebih tinggi. Namun tentunya investor harus berhati-hati terhadap kemungkinan terjadinya moral hazart serta adanya kemungkinan perusahaan tidak membagi dividen apabila proyek didanai dengan dana internal. Sebaliknya bagi investor yang cenderung bersifat risk averter, dapat mempertimbangkan investasi pada perusahaan dengan growth, non-debt tax shields, dan operating risk yang rendah sehingga pengawasan dari debtholder akan mendorong pemilihan investasi yang lebih konservatif.

Penelitian ini memiliki kelemahan dimana $\mathrm{R}^{2}$ relatif rendah. Hal ini disebabkan masih ada variabel lain yang berpengaruh signifikan tetapi tidak diikutsertakan dalam penelitian. Sehingga untuk penelitian berikutnya dapat dilakukan penambahan variabel lain yang mempengaruhi debt. Selain itu, penelitian ini hanya mengandalkan satu sumber data keuangan sehingga sangat memungkinkan dimana jumlah perusahaan yang diteliti jauh lebih sedikit daripada jumlah yang seharusnya digunakan. Dengan demikian, maka bagi penelitian-penelitian berikutnya diharapkan dapat memanfaatkan berbagai sumber data keuangan yang ada untuk kelengkapan data penelitian. 
Bagi peneliti yang ingin melakukan pengembangan terhadap penelitian ini, dapat melakukan pemilihan sektor yang lebih spesifik karena karakteristik bisnis tiap sektor dapat berbeda-beda. Selain itu juga dapat dilakukan penelitian mengenai faktor-faktor yang mempengaruhi speed of adjustment, perbandingan nilai speed of adjustment antar sektor atau antar market, keterkaitan antara speed of adjustment dengan market efficiency, dan berbagai pengembangan lainnya.

\section{DAFTAR REFERENSI}

Adam, T, dan V.K. Goyal, 2006, The Investment Opportunity Set and its Proxy Variables: Theory and Evidence, Working Paper, M.I.T. - Sloan School of Management.

Adedeji, A., 1998, Does The Pecking Order Hypothesis explain the Dividend Payout Ratio of Firm in The UK, Journal of Business Finance \& Acoounting, No. 25 : 1127-1 155.

Allen, F., dan R. Michaely, 2002, Payout Policy, Working Paper, Code: 01-21 B, The Wharton Financial Institution Center.

Anthony, J. H., dan K. Ramesh, 1992, Association between Accounting Performance Measure and Stock Price : a Test of the Life Cycle Hypothesis, Journal of Accounting and Economics, Vol. $15: 203-227$

Banking and Finance, Vol. 27: 1297-1321.

Brealey, R.A., dan S.C. Myers, 1991, Principles of Corporate Finance, $4^{\text {th }}$ edition, Mc Graw Hill, New York.

Brigham, Eugene F., and Michael C. Enhardt, 2005, Financial Management Theory and Practice, The Dryden Press, Fifth Edition, Publishing Service, Wiley International Edition.

Copeland, T.E., dan Weston, J.F., 1998, Manajemen Keuangan Edisi 8, Erlangga.

Damodaran, Aswath, 2001, Corporate Finance Theory and Practice, Second Edition, Hermitage Dewi, S. C., 2008, Pengaruh Kepemilikan Manajerial, Kepemilikan Institusional, Kebijakan Hutang, Profitabilitas dan Ukuran Perusahaan terhadap Kebijakan Dividen, Jurnal Bisnis dan Akuntansi, Vol. 10, No 1 : 48-57.

Fama, E.F., dan K.R. French, 2001, Disappearing Dividend: Changing Firm Characteristics or Lower Propensity to Pay?, Journal of Financial Economics, Vol.60: 3-43.

Fraser, L.M., dan Ormiston, A., 2004, Memahami Laporan Keuangan, Indeks Jakarta

Gaver, J.J., dan K.M. Gaver, 1993, Additional Evidence on the Association between the Investment Opportunity Set and Corporate Financing, Dividend and Compensation Policies, Journal of Accounting and Economics, Vol.16: 125-160.

Gitman, L.J., 2009, Principles of Managerial Finance, 12th Edition, Addison Wesley, Pearson Education Inc.

Grinstein, Y., dan R. Michaely, 2003, Institutional Holding and Payout Policy, Working Paper, Cornell University.

Gugler, K., 2003, Corporate Governance, Dividend Payout Policy, and the Interrelation between Dividend, R\&D, and Capital Investment, Journal of, 2004, Basic Econometrics, $4^{\text {th }}$ Edition, McGraw Hill International.

Gujarati, D.N Han, K. C., S. H. Lee, dan D.Y. Suk, 1999, Institutional Shareholders and Dividend, Journal of Financial and Strategic Decision, Spring, Vol. 12: hlm. 53-62.

Hartono, J., 1997, The Agency Cost Explanation for Dividend Payments: Empirical Evidence, Working Papers, Universitas Gadjah Mada.

Hatta, Atika J., 2002, Faktor-Faktor yang Mempengaruhi Kebijakan Dividen, Jurnal Akutansi dan Auditing Indonesia, Vol. 6, No. 2, Desember, hlm. 1-22

Ho, S.S.M., K.C.K. Lam, dan H. Sami, 2004, The Investment Opportunity Set, Director Ownership, and Corporate Policy: Evidence from Emerging Market, Journal of Corporate Finance, Vol. 10: 383-408.

Husnan, S., 2003, Dasar-Dasar Teori Portfolio dan Analisis Sekuritas, AMP YKPN.

Ismiyanti, Fitri dan M.M. Hanafi, 2003, Kepemilikan Manajerial, Kepemilikan Institusional, Risiko, Kebijakan Utang dan Kebijakan Dividen: Analisis Persamaan Simultan. Prosiding Simposium Nasional Akuntansi VI, Surabaya, 16-17 Oktober: hlm. 260-277.

Jacob, K.J., dan T. Ma, 2004, Are Ex Day Dividend Clientele Effect Dead? Dividend Yield 
Verse Dividend Size, Working Paper, JEL Classification Code G10, University of Montana.

Jensen, G.R., D.P. Solberg dan T.S. Zorn, 1992, Simultaneous Determination of Insider Ownership, Debt, and Dividend Policies, Journal of Financial and Quantitative Analysis, hlm. 247-264.

Jurusan Manajemen FBE Ubaya, 2009 Pedoman Penulisan Skripsi Jurusan Manajemen, Fakultas Bisnis dan Ekonomika, Universitas Surabaya.

Kania dan Bacon, 2005, What Factors Motivate the Corporate, ASBBS E-Journal, Vol 1. No 1.

Laporta, R., F. Lopez de Silanes, A. Shleifer dan R.W. Vishny, 1999, Agency Problems and Dividens Policies around the World, Working Paper, Harvard University

Mahadwarta, P. A., 2002, Interdependensi Antara Kebijakan Leverage dengan Kebijakan Dividen : Perspektif Teori Keagenan, Jurnal Riset Akuntansi, Manajemen dan Ekonomi 2, No. 2, 6 April 2002.

Mahadwartha, P. A. dan Hartono, J., 2002, Uji Teori Keagenan dalam Hubungan Interdependensi antara Kebijakan Hutang dengan Kebijakan Dividen, Simposium Nasional Akuntansi 5, 5-6 September 2002.

Megginson, W.L., 1997, Corporate Finance Theory, Addison Wesley.

Miller, M. H., dan Rock, K., 1985, Dividend Policy Under Asymetric Information, Journal of Finance, No. 40: hlm. 1031-1052.

Nuringsih, K, 2005, Analisis Pengaruh Kepemilikan Managerial, Kebijakan Hutang, ROA dan Ukuran Perusahaan terhadap Kebijakan Dividen : Studi 1995-1996, Jurnal Akuntansi dan Kevangan Indonesia Vol 2. No 2 : 103-123.

Nurfauziah, Harjito, D.A., Ringayati, A., Analisis Hubungan Simultan Antara Kepemilikan Manajerial, Risiko, Kebijakan Hutang dan Kebijakan Dividen Dalam Masalah Agensi, Kajian Bisnis dan Manajemen, Vol. 9, No. 2: hlm. 157-166.

Short, H., H. Zhang dan K. Keasey, 2002, The Link between Dividend Policy and Institutional Ownership, Journal of Corporate Finance, Vol. 8: hlm. 105-122.

Suharli, M. dan Oktorina, 2005, Memprediksi Tingkat Pengembalian Investasi Pada Equity Securities Melalui Rasio Profitabilitas, Likuiditas, dan Hutang Pada Perusahaan Publik di Jakarta. SNA VIII Solo, hlm. 288-295.

Suharli, M., 2007, Pengaruh Profitability dan Investsment Opportunity Set terhadap Kebijakan Dividen Tunai dengan Likuiditas Sebagai Variabel Penguat, Jurnal Ekonomi Akuntansi, Universitas Kristen Petra

Sujianto, Agus E., 2009, Aplikasi Statistik dengan SPSS, Jakarta: PT. Prestasi Pustakarya.

Sundjaja dan Barlian, 2003, Manajemen Keuangan, Literata Lintas Media.

Tabachnick, B. G., dan L.S. Fidell, 2007, Using Multivariate Statistics, 5th Edition, Allyn dan Bacon, Pearson Education Inc.

Thomsen, S., 2004, Blockholder Ownership, Dividend and Firm Value on Continental Europe, Working Paper, Danish Social Science Research Council. 